\title{
La autenticidad como eje diferenciador de marcas: su diseño estratégico mediante el uso de brandcepts
}

\author{
Humberto Consuegra / hconsuegra@enhebranding.info \\ Tecnológico Comfenalco \\ Víctor Quiñones-Cintrón / victorqnns@gmail.com \\ Universidad de Puerto Rico, Recinto de Río Piedras
}

Recibido: 21 de octubre de 2011

Aceptado: 7 de septiembre de 2012

\section{RESUMEN:}

Este trabajo responde a la interrogante de cuáles son los territorios emocionales que subyacen bajo el concepto de autenticidad para el posicionamiento en el mercado de un producto o marca. La metodología comprendió el uso de brancepts. Seis amas de casa participaron en una sesión focal para identificar las metáforas que vinculan al suero costeño colombiano con la autenticidad. El resultado de este estudio puede ser útil al estratega de mercadeo en el diseño del posicionamiento para el éxito de sus gestiones. Valida las perspectivas del método de los brandcepts y contiene sugerencias gerenciales para la implantación de los resultados.

Palabras clave: posicionamiento, brandcepts, estimulación de emociones, diferenciación estratégica, autenticidad, suero costeño

\section{ABSTRACT:}

This article evaluates the emotional territories that arise from the concept of authenticity in order to effectively position a brand or product in the market. Brandcepts were used as the basis of this study's methodology. Consequently, six

${ }^{1}$ Los autores reconocen, especialmente, el auspicio del Decanato de Estudios Graduados e Investigación (DEGI) de la Universidad de Puerto Rico, Recinto de Río Piedras, por otorgar una beca de viaje de investigación con motivos de materializar la recolección de datos en la ciudad de Cartagena de Indias, Colombia. Igualmente, se reconoce el auspicio de la Facultad de Ciencias Económicas de la Universidad de Cartagena, que con la dirección de su Decano, Raúl Quejada Pérez, facilitó el proceso de reclutamiento de participantes en la investigación y las instalaciones para el desarrollo de la sesión de grupo. 
housewives participated in a focus group in order to identify possible metaphors that could link suero costeño from Colombia with authenticity. The results of this study are very effective for the brand's strategist in order to successfully position the brand/ product in the market. The study also validates the use of brandcepts. In addition, the article contains effective managerial suggestions in order to better implement the study's results.

Keywords: positioning, brandcepts, emotions elicitation, strategic differentiation, authenticity, ethnic food seasoning

\section{INTRODUCCIÓN}

El significado que los consumidores le han conferido al concepto de la "autenticidad" en los productos (o "versión genuina" de un producto en relación a un lugar, región o país específicos) no está completamente claro y/o evidenciado para los mercadólogos (Groves, 2001) o especialistas que diseñan las estrategias orientadas a posicionar los productos en la mente de los clientes (Ries y Trout, 1982). Esta falta de claridad entre el consumidor y los gerentes de mercadeo se puede identificar en situaciones en las que un producto se posiciona y se promociona como auténtico (típicamente en conjunto con otros atributos), aunque no se puede confirmar que esta cualidad haya sido la razón determinante o decisiva del consumidor al momento de la compra del producto (Peterson, 2005). En realidad, los consumidores pueden comprar un producto sin que la autenticidad haya sido el valor principal que motive su decisión, aún cuando la misma haya sido referida por los gerentes de mercadeo. No obstante, existe un consenso general sobre la autenticidad como un concepto socialmente construido y aceptado por oferentes y demandantes (Beverland, 2005; Grayson y Martinec, 2004; Groves, 2001; Thompson, Rindfleisch y Arfel, 2006; Peterson, 2005), y también, como "idea popular construida localmente" (Lu y Fine, 1995). Incluso, este puede repercutir fuera de las fronteras nacionales (i.e., productos que plantean su autenticidad basándose en sus certificaciones de origen, como los vinos).

A pesar de no estar clara la utilidad del concepto autenticidad para los mercadólogos, este pudiera ser uno de los aspectos de batalla 
en la búsqueda de diferenciación (Beverland, 2005), que ayude a proporcionar alguna ventaja competitiva sostenible, aun cuando no sea el fundamento sobre el cual se erija una marca (Thompson, Rindfleisch y Arfel, 2006) ni que influya, en mayor medida, en las decisiones de determinados grupos de clientes. Por tanto, es apropiada la pregunta acerca de cuáles podrían ser los resultados si en el proceso de posicionamiento de un producto o marca, que busca aumentar sus posibilidades de éxito (Cooper, 1988), se evalúan, a su vez, los territorios emocionales (Woods, 2004) que subyacen tras la autenticidad.

Los autores gestionaron las posibles respuestas mediante un proyecto piloto en el que se evalúa la autenticidad del producto suero $\operatorname{costeño~}^{2}$ de la costa caribeña colombiana. En el proyecto intervino un grupo de mujeres trabajadoras y/o amas de casa, residentes en la ciudad de Cartagena de Indias. Aunque la investigación fue orientada hacia un producto en particular, las participantes también fueron expuestas a varios brandcepts o bocetos asociados a distintos productos. Dichos bocetos sirvieron como preámbulo al diálogo acerca del suero costeño y la autenticidad.

Los autores entendían, y así se confirmó, que los hallazgos determinarían la utilidad de ampliar este trabajo con el fin de incluir otros productos, entre cuyos atributos diferenciadores se aludiera a la autenticidad al momento de posicionarlos.

La primera parte de este trabajo presenta las distintas perspectivas de varios investigadores acerca del concepto de la autenticidad como parte del esfuerzo de mercadeo. Luego se incluye la descripción del método de investigación utilizado para conocer los territorios emocionales que subyacen a la autenticidad. El estudio finaliza con la presentación de los hallazgos, conclusiones y su pertinencia en la gestión de mercadeo.

\footnotetext{
${ }^{2}$ Producto originario de la costa Caribe colombiana, que para efectos prácticos será categorizado por los investigadores como 'dip étnico', para establecer una separación de la corriente principal que lo categoriza como simple derivado lácteo, esparcible, grasa e, incluso, queso.
} 


\section{LA AUTENTICIDAD EN LA GESTIÓN DE MERCADEO}

Aunque lo que significa el concepto autenticidad para los clientes no está completamente claro entre los gerentes de mercadeo, no por esto se carece de información referencial que plantee y discuta aspectos relacionados con la estrategia de posicionamiento correspondiente a un producto. Esta afirmación se evidencia a continuación.

\section{LA PROYECCIÓN DE LA AUTENTICIDAD DE LOS PRODUCTOS}

Beverland (2005, 2006) ha identificado seis atributos de autenticidad en marcas exitosas: herencia y linaje, consistencia de estilo, compromiso con la calidad, relación con el lugar, método de producción y subordinación de los motivos comerciales. Peterson (2005), por su parte, en un enfoque historiográfico, manifiesta otras seis fuentes desde las que se puede identificar la autenticidad en los productos: identidad étnica/cultural, elasticidad de membresía de grupo, identidad de estatus, búsqueda de experiencia auténtica, mediación tecnológica y autoconstrucción. A su vez, Alexander (2009) enriquece el constructo de Beverland $(2005,2006)$ al aludir a una marca de consumo masivo (cerveza Braun); jerarquiza la forma, como en el caso particular del producto aludido, y fusiona algunos atributos (por ejemplo: herencia y linaje, compromiso con la calidad y método de producción, imbuidos en consistencia de estilo). Además, reconoce que no todos los atributos participan de la misma función en la percepción de la autenticidad.

Lo particularmente valioso de los hallazgos de Alexander (2009) es que su evidencia sugiere que los atributos beverlandianos no necesariamente son transferibles a cualquier contexto y que, en caso de que lo sean, participan, de lo que podría denominarse, efecto caleidoscopio. Esto es debido a que, ante la presencia de los mismos componentes, pueden generarse imágenes diferentes de acuerdo con el manejo del concepto autenticidad. Si se apela a lo planteado por Lu y Fine (1995), se puede formular una pregunta clave a los gerentes de mercadeo: ¿cómo planear y proceder a operacionalizar 
la autenticidad ante la audiencia de interés, [debido al comentario de Alexander]?

La respuesta inmediata y práctica es que, de existir algún posicionamiento favorable sobre el producto aceptado por el mercado, vale más mantenerlo de esa forma que intentar alterarlo. Así pues, debido a que en el entorno de los alimentos, por ejemplo, los consumidores usan frecuentemente la autenticidad para referirse a una versión genuina de un producto en relación con un lugar, región o país específico (Groves, 2001), el gerente de mercadeo debería funcionar con autenticidad al mantener la referencia de lo aceptado por el mercado sin exagerar su impacto (i.e., suero costeño, colombiano). Es posible, incluso, clasificar de étnica toda una manifestación gastronómica, debido a su posicionamiento favorable y, con esa clasificación, destacar los valores específicos del entorno en que son ofrecidos (i.e., gastronomía gallega). Esta sugerencia puede aplicarse también a situaciones en las que se ofrece el producto fuera del entorno con que se asocia el mismo. Lu y Fine (1995) reconocen que los restaurantes chinos localizados fuera de los entornos del país apuestan a establecer una clientela foránea; por lo tanto, tienden a ajustar sus propuestas a los gustos del lugar donde se localizan; sacrifican parte de su legitimidad sin perder los distintivos que los mantienen como gestores auténticos ante el juicio de los clientes.

\section{LA AUTENTICIDAD COMO PARTE DE LA PROMESA DE VALOR A LOS MERCADOS}

Grönroos (2006) ha señalado que ningún esfuerzo de mercadeo entrega (delivers) valor (beneficios vs. costos asociados a la adquisición de productos) a los mercados. Más bien, el gerente de mercadeo busca cumplir con las expectativas que generan las ofertas de valor prometidas al cliente (Grönroos, 2006). El gerente de mercadeo debe entender que las expectativas (generadas por las promesas) que no se les cumplan a los consumidores, obtendrán en el mercado consecuencias desfavorables, debido a la insatisfacción que provoca el incumplimiento. Calonius (1986) define el concepto promesas como "declaraciones... hechas a terceros o 
a uno mismo,... que indican que alguien proveerá... algo específico a otro". A su vez, añade que todas las promesas estarán sujetas a la interpretación de los interlocutores.

En esta investigación, el concepto autenticidad se ha asociado con la procedencia $u$ origen del producto que se ha considerado para este estudio: el suero costeño procedente de la región de Colombia en el Caribe. La pregunta que compete, en este momento, es si el gerente de mercadeo debe prometer autenticidad como parte del posicionamiento del producto. Como los proveedores del suero costeño alegan que la procedencia de este es del lugar que se ha indicado, entonces es adecuado incluirlo como parte de la declaración de posicionamiento de este producto. Sin embargo, la importancia y validez de dicho alegato siempre estará sujeta a la interpretación que otorgue el mercado a una consideración que pudiera no ser un determinante de su compra. Si el mercado considera importante la autenticidad del suero, pero no como determinante de su compra, ¿se podrá valorar como parte del posicionamiento del suero? En la literatura sobre autenticación (Alexander, 2009; Beverland, 2005; Beverland, 2006; Beverland y Farrely, 2010; Peterson, 2005), prevalece, en ocasiones, la impresión de que el posicionamiento de la autenticidad solo es posible para cierto tipo de categorías existentes, y que su espacio no es generalizable.

\section{LA INVESTIGACIÓN SOBRE AUTENTICIDAD}

Un intento realizado para generar una hermenéutica del estado del arte de la autenticidad vinculada a la investigación en mercadeo sugiere situar tres dimensiones en los estudios que se realicen: el enfoque, el alcance y el método. Para tales efectos, enfoque se refiere al(los) agente(s) del mercado que interviene(n) en la investigación: bien sea la oferta, la demanda o ambos; el alcance alude al área de mercado considerada por el(los) investigador(es), y el método especifica los mecanismos empleados para canalizar la búsqueda que se ha predeterminado como relevante para la investigación. La Figura 1 presenta un diagrama de las tres dimensiones indicadas en relación con las investigaciones llevadas a cabo sobre la autenticidad de los productos. 
Figura 1:

La autenticidad en la literatura de mercadeo

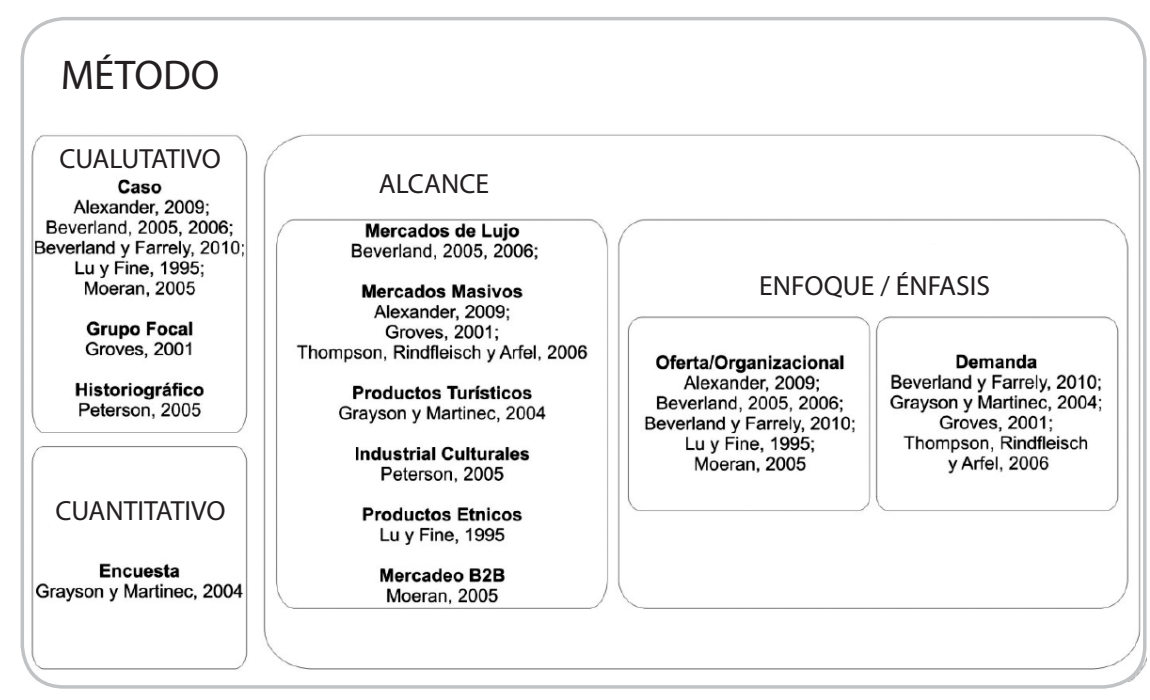

Fuente: elaboración propia.

Como se evidencia, una buena parte de la investigación sobre la noción de autenticidad en mercadeo se ha orientado hacia el uso más frecuente de una metodología cualitativa, especialmente en el estudio de casos. El uso de métodos cualitativos para llevar a cabo una investigación acerca del tema de la autenticidad, un concepto de construcción social, puede ocasionarlo el que éste propicia la intervención activa de los participantes. De esta manera, se producen discusiones y se identifican las asociaciones, que le permiten al gerente de mercadeo que investiga orientarse acerca de lo que piensa el consumidor cuando se le plantean temas abstractos, que el lenguaje metafórico logra descubrir (Zaltman y Zaltman, 2008). Woods (2004) ha trabajado en el diseño de lo que llamó brandcepts, una metodología cualitativa, que permite asociar emociones y productos mediante estimulaciones provocadoras de expresiones verbales, que son más difíciles de lograr por medio de otros métodos de investigación. Los resultados obtenidos mediante los trabajos de Zaltman y Zaltman (2008) y los de Woods (2004), aunque se llevaron a cabo mediante procesos diferentes, han esclarecido dudas acerca 
del comportamiento de los clientes cuando deciden las compras y su uso. Además, han permitido que se cuente con información fundamental para las gestiones requeridas de segmentación y posicionamiento en todo esfuerzo estratégico en mercadeo (Kotler y Keller, 2009).

\section{MÉtodo de INVESTIGACIÓN}

A continuación se detalla el método de investigación utilizado por los autores para este proyecto piloto, basado en la perspectiva de Woods (2004), conocida como brandcepts. El objetivo de este estudio ha sido conocer los territorios emocionales que subyacen tras la autenticidad al posicionar un producto como típico de la costa caribeña colombiana: el suero costeño como dip étnico. Peterson (2005) ha identificado la étnia como una fuente de autenticidad en su estudio basado en la literatura sobre este tema. En este trabajo se tomaron en cuenta las fuentes de información relacionadas con los aspectos de la autenticidad: origen, tradición, legitimidad y novedad. Al tratarse de solo una sesión de grupo, con no más de 6 participantes, los resultados obtenidos, aunque proporcionaron ideas valiosas acerca de la percepción de los consumidores sobre la noción de autenticidad, no podrán ser generalizados sobre la población aludida.

\section{Metodología del PROCESO de INVESTIGACIÓN}

La investigación tuvo cuatro fases:

- Desarrollo de brandcepts o bocetos como instrumentos de estímulo

- Reclutamiento de participantes

- Desarrollo de sesión de grupo

- Análisis e interpretación de datos 


\section{DESARROLLO DE BRANDCEPTS COMO INSTRUMENTO DE ESTÍMULO}

Los brandcepts son estimulaciones sobre lo que es o podría ser una marca, que ayudan a los participantes a filtrar las emociones en el proceso de investigación, y, producto de esto, a asociar marcas con emociones concretas, sobre las cuales típicamente no son capaces de expresarse por sí mismos (Woods, 2004). Desde la perspectiva operacional, los brandcepts o estimulaciones, se presentan a manera de bocetos, ya que una de las características que los validan es su formato áspero- líneas escritas de manera simple, incluso a mano, e imágenes conscientemente apropiadas de otras fuentes.

Para la investigación se desarrollaron 32 brandcepts o bocetos. Se utilizaron como criterios de creación la apelación a cuatro áreas de la noción de lo auténtico: origen, tradición, legitimidad y novedad. Cada una de las áreas tuvo un total de 8 brandcepts, de tal forma que se garantizó el balance en la oferta y que fueran los participantes quienes inclinaran la balanza hacia algún área en particular, si alguna.

\section{RECLUTAMIENTO DE PARTICIPANTES}

De acuerdo con la información obtenida de marketingnews.com. co (2010), en su avance sobre las 13 tendencias del estilo de vida del consumidor colombiano, hay dos tendencias importantes que describen dicho sector: por un lado, la mujer colombiana se ha convertido en una súper mujer, que ya no solo cría a los hijos y asume las tareas del hogar (una de las cuales es hacer el mercado), sino que también trabaja. En segundo lugar, los hogares en general, después de la crisis, han experimentado lo que puede denominarse como un repliegue hacia la casa, donde cocinar es una de las actividades que se presentan como opción para ahorrar dinero sin renunciar a satisfacción.

Dado lo anteriormente expresado, para este proyecto piloto se reclutaron 6 mujeres con las siguientes características: amas de casa o trabajadoras, encargadas de hacer el trabajo del hogar y sus compras 
de alimentos, oriundas de la costa caribeña colombiana ${ }^{3}$ residentes en Cartagena de Indias, quienes nunca hubiesen participado en sesiones focales y con disponibilidad para participar en la sesión por espacio de una o dos horas.

Para el reclutamiento fue necesaria la intermediación. Como es frecuente depender de las universidades como fuente de participantes en investigaciones de mercadeo, los investigadores recurrieron a la Universidad de Cartagena, pues consideraron que ha desarrollado un sistema de comunicación de medios electrónicos y, por lo tanto, podía garantizar la etapa de reclutamiento de las personas con el perfil indicado.

\section{DESARROLLO DE SESIÓN DE GRUPO}

- Exposición a los brandcepts - Las participantes reclutadas se llevaron a una sala, donde aparecían desplegadas una serie de imágenes en bocetos (brandcepts). Una vez en el lugar, se les pidió observar y evaluar los bocetos en función de sus experiencias y/o deseos en torno a productos catalogados como auténticos. Se les indicó que el tiempo de esta fase no sobrepasaría los 30 minutos y que no existía restricción alguna para manipular (alterar) las imágenes o socializar con el resto de las participantes. Además, se les aconsejó que era valioso anotar las impresiones más relevantes, ya que serían discutidas posteriormente con el moderador (uno de los investigadores en el proyecto).

- Sesión de socialización - Luego de la fase de observación y de acuerdo con una guía de temas, se mantuvo un diálogo entre el moderador y las participantes. No se restringió el contenido de los diálogos debido a que se vislumbró que podían generar aspectos pertinentes al tema indagado, no anticipados por el

${ }^{3}$ Personas oriundas de la costa norte colombiana, representadas por gente de ciudades como Cartagena, Barranquilla o Santa Marta, entre otras. 
moderador. A continuación se incluyen los temas principales abordados en el diálogo con las participantes:

- La autenticidad y su determinación al momento de comprar.

- La representación de lo auténtico en los bocetos observados y productos asociados con las imágenes incluidas en los mismos.

- La importancia de lo auténtico en productos costeños y la identificación de lo costeño en los bocetos observados.

- El suero costeño como producto auténtico: perspectivas personales y perspectivas provistas por proveedores de los sueros disponibles para su compra.

- Cocreación - Una vez se consideró conveniente, el moderador introdujo a las participantes a una nueva interacción con los brandcepts, pero esta vez, se tenía el suero costeño como referente. Se les requirió a las participantes que evaluaran los brandcepts en función del producto aludido, que se sintieran libres de rehacer el boceto o de trasponer imágenes con otros bocetos o, sencillamente, de descartar un brandcept como no representativo.

- Análisis e interpretación de datos - La interpretación de las expresiones vertidas por las participantes no se limitó a las narrativas logradas una vez concluida la sesión. Durante la sesión se procedió a tomar ventaja de lo expresado al modificar y adaptar interrogantes anticipadas, debido a que podrían ser aportes al proceso. Se grabaron en audio los datos de la sesión de grupo y luego se transcribieron para el procedimiento de las categorizaciones, abstracciones, comparaciones, dimensiones, integraciones e iteraciones correspondientes (Spiggle, 1994). 


\section{Resultados}

\section{Preludio emocional: confusión e inseguridad}

Chitturi, Raghunathan y Mahajan (2008) ofrecen una lista de 14 emociones (entre positivas y negativas) que los participantes de su investigación mostraron ante la exposición a estímulos que pretendían indagar la percepción de beneficios utilitarios y/o hedónicos en diferentes categorías de productos. Tales emociones fueron: culpa, ansiedad, tristeza, insatisfacción, pesar, ira, decepción, sorpresa, seguridad, confianza, excitación, satisfacción, alegría y deleite. En esta investigación era posible que surgieran otras emociones tales como: orgullo, antipatía, exaltación, empatía, nostalgia y confusión, durante el periodo de la interacción activa y social del grupo de amas de casa, en torno a las estimulaciones emocionales que pudiesen provocar los bocetos (brandcepts). Los bocetos fueron los únicos catalizadores de las emociones de las participantes, debido a que no había una marca específica existente sobre la cual se indagara, tal como sugiere Woods (2004).

$\mathrm{Al}$ principio de la sesión, a pesar de que no existía el riesgo de pérdidas económicas ni de exponer ningún aspecto vital, se pudieron detectar sensaciones de confusión e inseguridad como antítesis de la emoción de seguridad incluida en las 14 emociones de Chitturi, Raghunathan y Mahajan. Las participantes confirmaron la posibilidad de que surgieran otras emociones distintas de las planteadas por Chitturi, Raghunathan y Mahajan, cuando afirmaron que desconocían qué hacer o cómo proceder una vez vistos los bocetos. Sin embargo, luego de las instrucciones, procedieron a mirarlos detenidamente y a escribir lo que cada boceto significaba para ellas.

De alguna manera, esto sugiere que la presencia de marcas o de categorías de productos que se pueden evaluar de manera explícita, transmite, aunque sea bajo competencia, una sensación de seguridad acerca del tipo de elección que se realiza. Es como si las marcas crearan marcos de decisión, pues estas se asocian a ciertas categorías, beneficios, aspiraciones, a las que el cliente se acoge (Aaker, 1997). 


\section{EL ORGULLO dE SER COSTEÑO, MÁS ALLÁ DE TODO}

Entre los atributos que Beverland (2005, 2006) propone para el concepto autenticidad, se seleccionaron los de herencia y linaje y relación con el lugar, como sinónimos propios de la categoría Origen. Sobre el particular, Lewis y Bridger (2000) también sugieren asociar la relación con un lugar en los esfuerzos por conferir halo de autenticidad a un producto. Asímismo, Peterson (2005) se refiere a la identidad étnica y cultural. De estos atributos se puede derivar una emoción natural de orgullo, evidenciada en la Figura 2.

Figura 2:

Brandcepts: emoción de orgullo vinculada a Origen
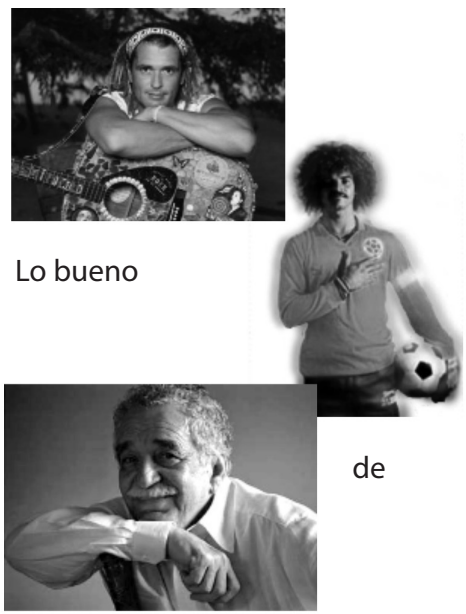

donde eres.

Fuente: elaboración propia.

Varias de las participantes coinciden con el brandcept de la Figura 2 para declarar lo que es orgullo para ellas. El brandcept trasmite directamente esta sensación, puesto que los individuos incluidos son de origen colombiano costeño. Además, en términos de Grayson y Martinec (2004), representan la iconicidad de la autenticidad atribuida a cada uno de ellos en sus respectivos campos de acción: 
Carlos Vives, en la música popular; Carlos El Pibe Valderrama, en el fútbol y Gabriel García Márquez, en la literatura.

Es meritorio destacar que entre las participantes se asoció el brandcept a hablar de su comida, lo que podría favorecer el vincular un producto (i.e., el suero costeño) al lugar de nacimiento como base de autenticidad. Lo expresado es consistente con lo anotado por Herrera (2010) en el sentido de que en Colombia en "los sabores de ciertos productos tienen fuerte ascendencia regional en su preparación”. Groves (2001) llama versión genuina a la asociación entre productos y el lugar de procedencia (el suero costeño podría coincidir con esta perspectiva).

\section{LOS SIMPSON PODRÁN SER AUTÉNTICOS A SU MODO, PERO DESPIERTAN AVERSIÓN}

Los Simpson, según Lewis y Bridger (2000), son portadores de uno de los atributos derivados de la autenticidad: la originalidad. Para efectos de la investigación, fueron dos los fundamentos que determinaron el diseño de un brandcept en torno a Los Simpson: primero, son una familia y, como tal, se pretendía presentarlos como evocación de la importancia de ésta, para los costeños; segundo, se quiso poner a prueba el punto de vista de su autenticidad.

Figura 3:

Brandcepts: Los Simpson como familia, por encima de todo...

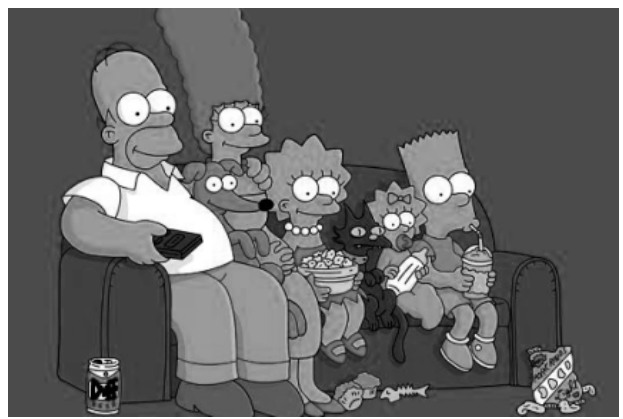

Fuente: elaboración propia. 
Cuando a las participantes se les requirió que de las piezas expuestas seleccionaran aquella(s) que, a su juicio, mejor representaba(n) el criterio de autenticidad, espontáneamente, surgió la elección del brandcept de los Simpson (Figura 3) como su antítesis. No obstante, las participantes estuvieron a favor de la autenticidad de Los Simpson como familia. Sin embargo, lo expresado no sugiere que cuando se reconoce un elemento como auténtico, no necesariamente se convierte en uno considerado aceptable. Esto queda evidenciado cuando, después de que se reconociera la autenticidad de los Simpson como familia, se les pregunta a las participantes si excluir este brandcept de la exposición de bocetos la convertiría en una exhibición más auténtica. Las participantes respondieron que "tal vez no, pero no congeniamos con los Simpson".

El disgusto expresado por las participantes acerca de la forma de comportamiento de los Simpson parece indicar que para un mercado, cualquier controversia entre conceptos aceptables (los Simpson como familia) y no aceptables (el comportamiento de la familia Simpson) podría provocarle consecuencias desfavorables (imagen, posicionamiento, ventas) a un producto que desee legitimar su autenticidad. Este podría ser el resultado, particularmente, si los aspectos que no son aceptables logran más protagonismo que lo esperado (como sucedió en el brandcept 3).

\section{LA AUTENTICIDAD ES UBICUA}

Se les preguntó a las participantes lo siguiente: ¿Qué es ser auténtico? Las respuestas se pueden sintetizar en el siguiente tipo de expresión: "ser uno mismo...no mostrar una cara que no es". Previo a la presentación del grupo del producto objeto de esta investigación (el suero costeño), las participantes expresaron los que podían posicionarse como auténticos productos de distinta naturaleza. Aludieron a vestidos, productos alimenticios, productos de aseo personal e, incluso, a personas.

Cuando los moderadores inquirieron sobre lo que no es auténtico para las participantes, estas respondieron: 
- "Yo pienso que es... como las modas que hay ahora... uno ve que las gorras a medio lado... entonces uno ve a los muchachitos que con las gorras por aquí...los pantalones por acá... eso tiene como más influencia de afuera que de acá..."

- "Uno mira a la mujer ahora muy liberada... muy arreglada... entonces ya no es una belleza auténtica..."

- “... no con tanta cosa como hay ahora, que la silicona, que la lipo ${ }^{4}$ que esto otro..."

- "Uno ve muchas veces una fruta enlatada... eso no es auténtico... porque ya eso tiene químico".

De las expresiones anteriores se infiere que para este grupo, la autenticidad está ligada al origen, a lo que se asocia con la génesis de algo o de alguien. Como indicó una de las participantes al aludir a lo no auténtico: “... eso tiene como más influencia de afuera que de acá”. Igualmente, el valor de lo natural y fresco cobra relevancia para validar un producto como auténtico. Esto se deduce del significado de las atribuciones negativas a la presencia expresadas por las participantes como: mucho arreglo, o de silicona, lipo y esto otro. En la Figura 4, se incluyen los brandcepts que también se asociaron con autenticidad.

Entre los brandcepts que asociaron las participantes con autenticidad, se pudieron identificar tres categorías de brandcepts creados que, según ellas, validan el concepto autenticidad: (1) origen (en Figura 2); (2) tradición (en Figura 4) y (3) legitimidad (en Figura 4). La primera categoría (origen), incluida en la Figura 2, responde a los atributos de herencia y linaje (Beverland, 2005; Beverland, 2006) y de relación con el lugar (Beverland, 2005; Beverland, 2006; Lewis y Bridger, 2000). La segunda categoría (tradición), incluida en la Figura 4, está vinculada a relación con lugar (Beverland, 2005; Beverland, 2006; Lewis y Bridger, 2000). La tercera categoría (legitimidad), ilustrada en la Figura 4, es una categoría que se creó basada en la validación que surge por parte de agentes diferentes a los consumidores (ejemplo: asociaciones, gobierno y otros), quienes

4 Contracción gramatical para referirse a la intervención quirúrgicoestética llamada liposucción. 
Figura 4:

Brandcepts que también apelaron a la autenticidad
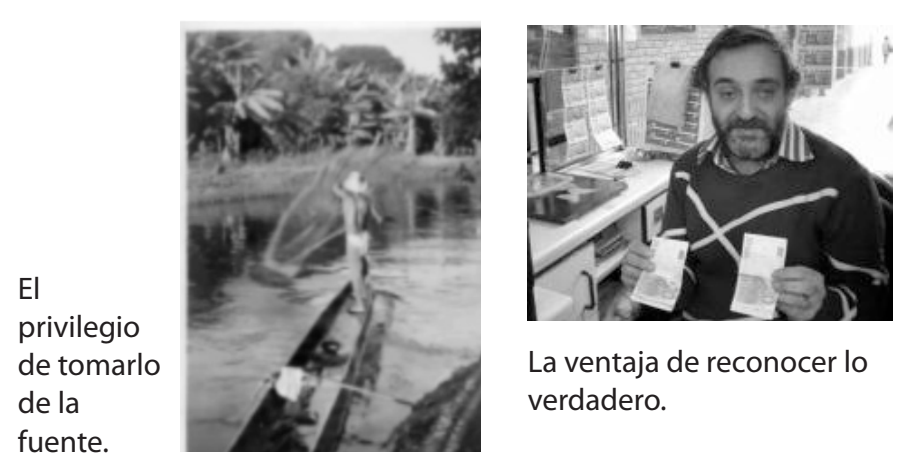

La ventaja de reconocer lo verdadero.

Una prueba
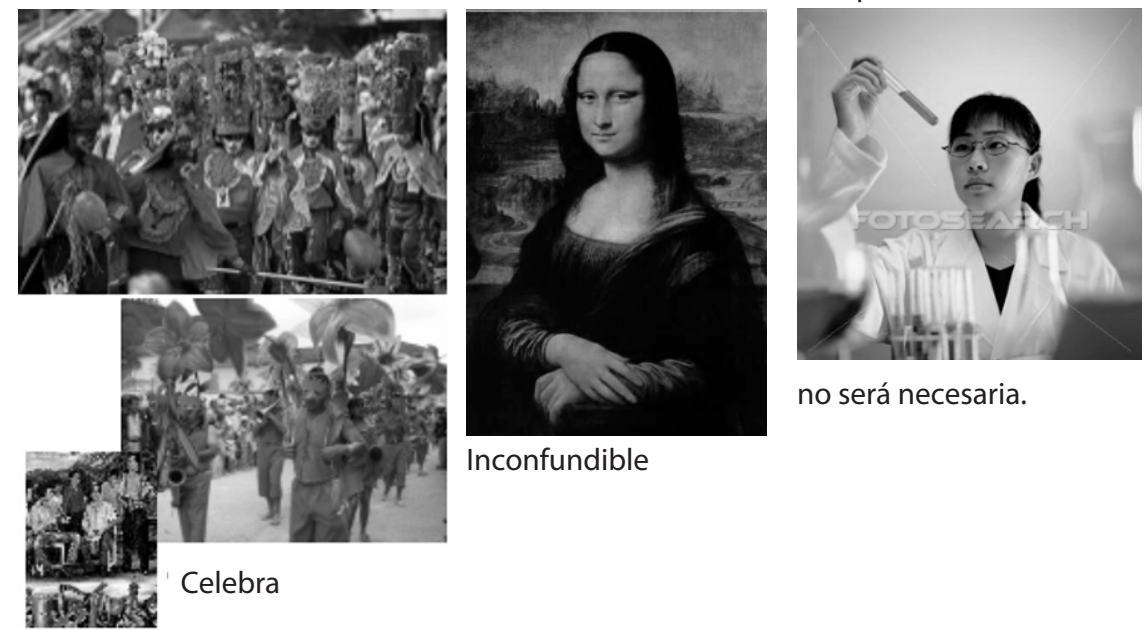

no será necesaria.

Inconfundible

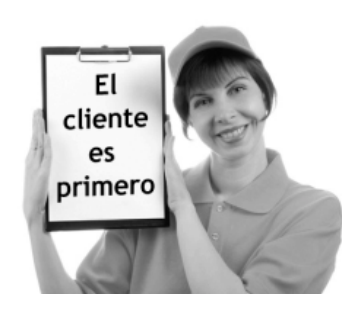

Que

sea

verdad.

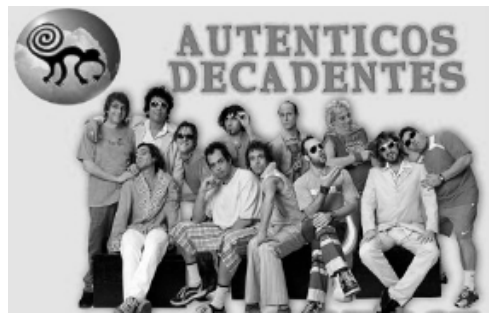

Somos los

originales.

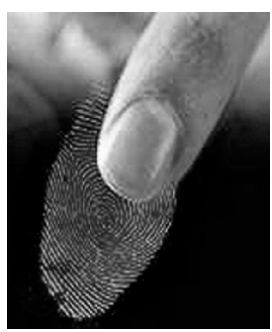

Te identificarás con nosotros.

Fuente: elaboración propia. 
pueden convertirse en mediadores influyentes del consumo de un producto. Esta categoría no fue incluida por las participantes como parte de los bocetos asociados a la autenticidad. La Figura 5 incluye bocetos orientados hacia el concepto novedad tampoco incluída por las participantes como parte de la autenticidad.

Figura 5:

Brandcepts orientados hacia el concepto novedad (no incluidos como parte de lo auténtico por las participantes de la investigación)

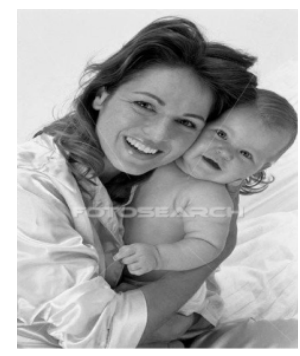

Algo nuevo tiene un auténtico parecido a ti.

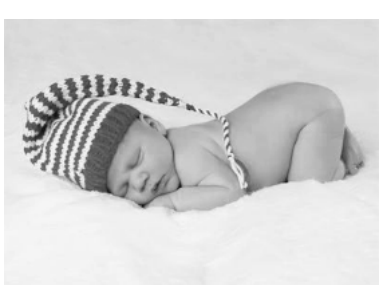

Auténtico desde su nacimiento.

Hay cosas por conocer...

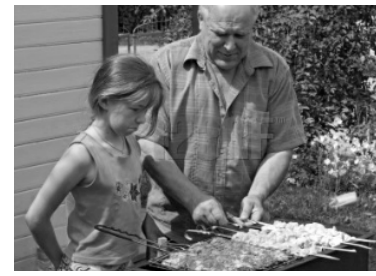

es tu turno.

No ser como los demás.

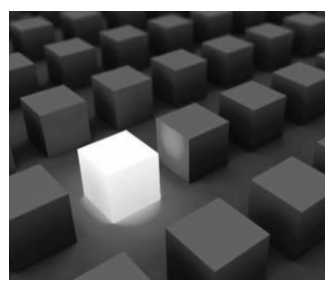

Disfrutar lo que te gusta.

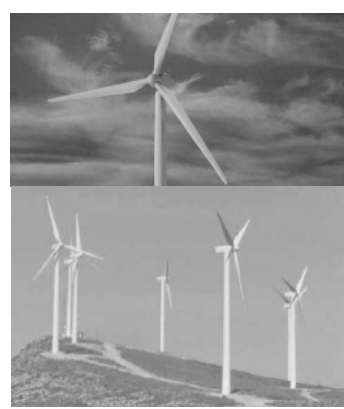

Ábrete a un aire fresco, como tú.

La satisfacción sale a flote; algo que antes no tenías.
¿Qué hay de nuevo?

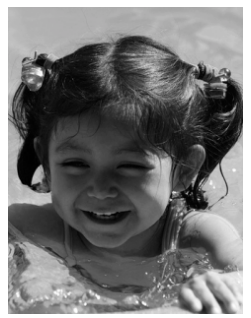

FORUM EMPRESARIAL VOL. 17. NÚM. 2 • INVIERNO 2012-2013 
Las participantes también fueron expuestas a varios brandcepts asociados a productos. Dichos bocetos sirvieron como preámbulo al diálogo acerca del producto suero costeño y el concepto de la autenticidad. Los siguientes brandcepts fueron los más comentados:

Figura 6:

\section{Brandcepts de productos evocados}

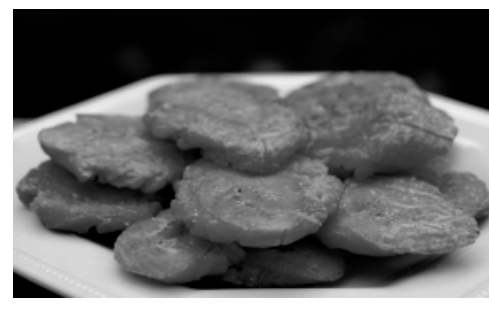

Nos gusta hacerlo juntos.

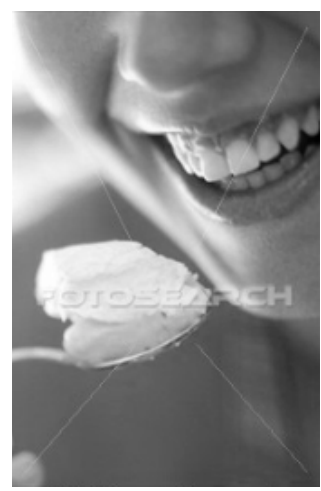

Placer innegable

Fuente: elaboración propia.

Los comentarios de las participantes fueron los siguientes:

- "El helado me produjo una tentación... yo quiero comerme ese helado... y si es de galleta mucho más..."

- "Los patacones ${ }^{5}$ la comida... es importante... bueno cuando tú vas donde el carretillero ${ }^{6}$ quieres un plátano grande... un plátano que se vea bonito... eso llama la atención...

${ }^{5}$ Patacón es la denominación que se le da en Colombia a lo que en Puerto Rico y otros países del Caribe se le llama "tostón”.

${ }^{6}$ Persona que distribuye al detalle productos mayormente alimenticios como plátano, yuca, ñame, frutas y verduras, empujando una carreta que contiene su oferta y entonando un pregón personal como anuncio de su presencia. Este intermediario es típico de los barrios populares de la ciudad de Cartagena. Contribuye a ampliar las opciones disponibles complementando la oferta de las tiendas de barrio. 
entonces entre más grande sea el plátano más rápido uno lo va comprando... le gusta mucho a los niños también... el patacón con el pescado".

Las evocaciones del helado y los patacones parecían reflejar deleite personal (Chitturi, Raghunathan y Mahajan, 2008). El deleite también se plantea como una expresión colectiva, aunque la decisión acerca de lo que contiene el potencial de deleitar a los demás provenga de una sola persona. Herrera (2010) valida estos hallazgos, pues este ha afirmado que "la primera prueba está presente en nuestros primeros años y hasta cierta edad (más o menos a los 5 años), son nuestros padres [o familiares mayores] los que definen esa experiencia”.

Es importante señalar que, de manera espontánea, el comentario de una de las participantes acerca de los patacones produjo, que otra planteara, que el suero costeño era un producto auténtico. Esto conllevó una redirección hacia ese producto en la dinámica de grupo.

\section{SUERO COSTEÑO: DELEITE Y CONEXIÓN AUTÉNTICOS}

Las siguientes expresiones: "Me fascina con yuca...", "delicioso con yuca... con ñame, yuca, sabroso...", se suscitaron cuando se aprovechó la coyuntura de la mención del producto suero costeño de parte de las participantes. Las expresiones parecían manifestar deleite, acompañado de una excitación colectiva que se manifestó en risas y se gesticuló en miradas cómplices, en lamida de labios y en movimientos momentáneos de inquietud.

No es de extrañar que uno de los atributos generadores del deleite evocado sea el sabor. De hecho, el sabor ya ha sido antes considerado como un atributo jerárquicamente superior a otros, como por ejemplo, lo saludable, en el caso de productos lácteos (Palojoki y Tuomi-Gröhn, 2001). Además de que aquel puede revelar la procedencia del producto por estar fuertemente arraigado a lugares específicos (Herrera, 2010) y, de esta manera, se expone su condición de versión genuina (Groves, 2001). 
El suero costeño ha sido nombrado en investigaciones recientes llevadasa cabo en lugarescercanos (geográficay gastronómicamente) a la ciudad de Cartagena, Colombia, como uno de los productos alimenticios representativos de la costa colombiana (Martínez, 2009). Incluso, se vincula a manifestaciones estéticas de la cultura como el Carnaval de Barranquilla, lo cual coincide con la metáfora profunda de conexión (Zaltman y Zaltman, 2008), en tanto genera asociaciones directas respecto al origen, bien sea de las personas, bien de los productos que estas consumen. Además del valor funcional atribuido, contiene, a su vez, un valor hedónicocultural.

\section{SUERO COSTEÑO: EL EFECTO CALEIDOSCOPIO DERIVADO DE LOS BRANDCEPTS}

Una de los puntos de vista planteados es que la autenticidad puede suscitar un efecto caleidoscopio, debido a que con los mismos componentes (los brandcepts en este caso) construidos a partir de ciertos criterios-atributos, se pueden generar imágenes diferentes acordes con el movimiento realizado (el paso de una categoría a otra, según el interés del investigador).

La siguiente imagen (Figura 7), por ejemplo, muestra cómo ante un nuevo marco teórico planteado para analizar las emociones que puedan generar la noción de autenticidad (en el marco del suero costeño), hay imágenes que se tornan recurrentes, tales como el brandcept que contiene el siguiente mensaje de lo bueno de dónde eres, y aquellos con los mensajes inconfundible y placer innegable, aunque, a su vez, hay otros que se incorporan con significación específica para la categoría.

Nótese cómo algunas expresiones están ligadas al valor en uso (Grönroos, 2006) del producto; mientras otras son el resultado de la mera evocación del producto, que están antecedidas, a su vez, por una relación con el mismo. Por ejemplo, la participante que trae a colación la prueba de sabor, llega a su conclusión después de verificar relaciones de facto, esto es, realiza indexaciones (Grayson y Martinec, 2004), así como la participante que presenta una situación en la cual 
Figura 7:

Brandcepts relacionados con el suero costeño

(incluye comentarios de las participantes)

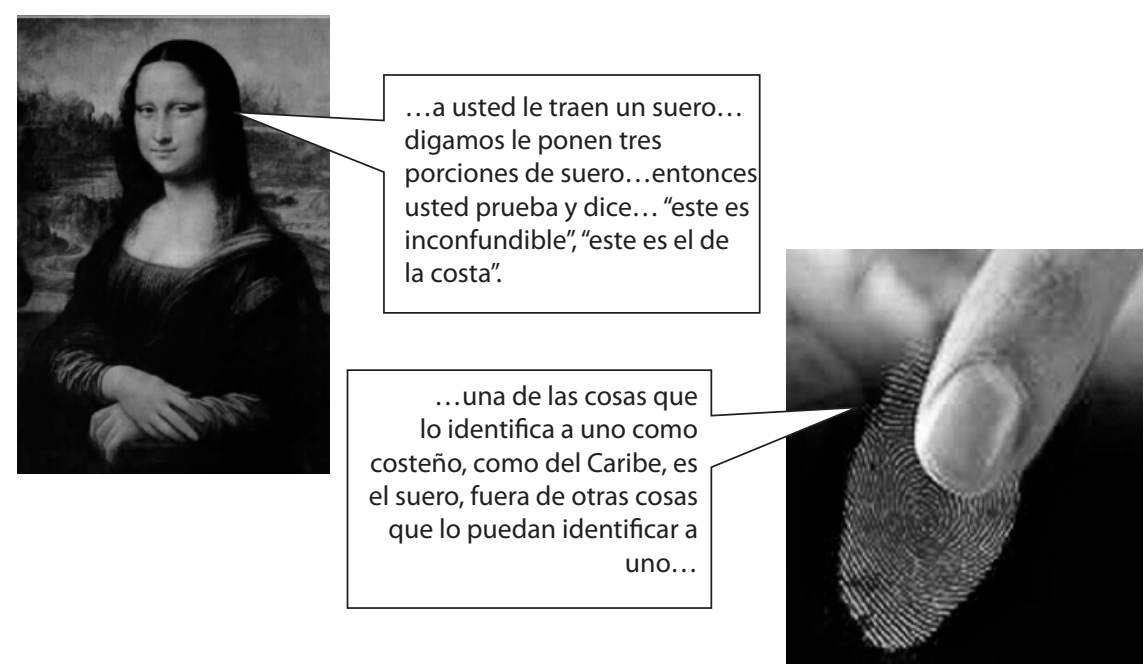

Te identifucarás con

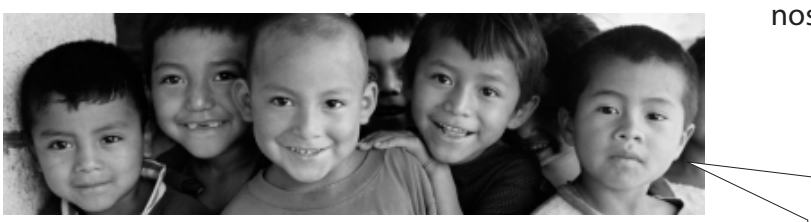

Nuestra sinceridad

es incuestionable.

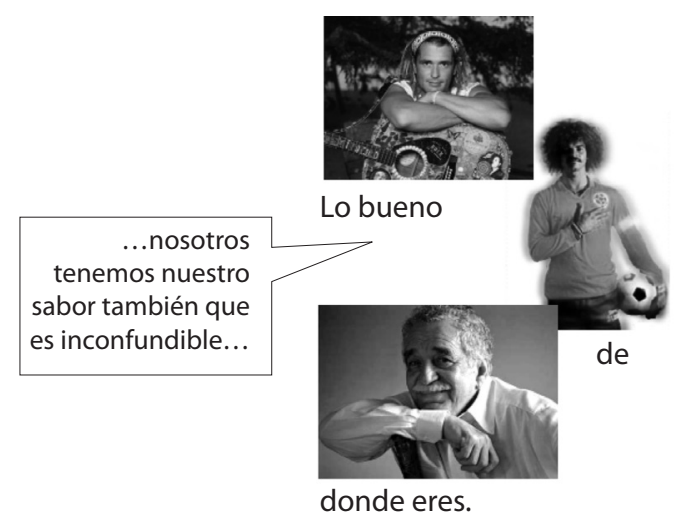

Hay que ser sincero, si el suero es malo, es malo, a mí me gusta el suero que sea original, que sea espeso, punto. La sinceridad ante todo. Porque a mí me dicen "niña llévese este suero" y yo digo "no, a mi me gusta éste que tiene más sabor costeño"...Soy sincera, digo lo que es...

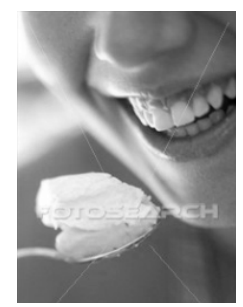

Placer innegable

Fuente: elaboración propia. 
rechaza una propuesta recibida. Mientras tanto, expresiones como nosotros tenemos nuestro sabor también, una de las cosas que lo identifica a uno como costeño... y el placer que te produce el suero con el arroz..., están en el plano de las elaboraciones mentales.

Nuevamente, la identidad étnico-cultural (Peterson, 2005) se exalta a través de la conexión (Zaltman y Zaltman, 2008) que genera el suero costeño con el origen de las personas. Se expresa en una manifestación de orgullo acerca de la aceptación de la procedencia. La sinceridad, por su parte, se presenta como un valor incorporado en lo que se comunica a otros. También, este puede ser desdoblado como en el hecho de preparar el suero de la forma que debe ser, es decir, debe adquirir compromiso con la calidad y el método de producción y subordinar, en alguna medida, los motivos comerciales (Beverland, 2005; Beverland, 2006).

\section{IMPLICACIONES GERENCIALES DE LOS HALLAZGOS EN CUANTO AL ESFUERZO DE MERCADEO}

Varias son las áreas del esfuerzo de mercadeo que podrían beneficiarse de la orientación que se logra obtener de los brandcepts (sin que ello implique que las decisiones finales del esfuerzo de mercadeo tendrán como determinante el ejercicio con los bocetos). Las áreas son las siguientes: en primer lugar, desde el ángulo estratégico, se beneficia la gestión de segmentación del mercado. Esta permite identificar, al menos, de manera preliminar, a quién valdría la pena plantearle el concepto de autenticidad y también el concepto de la diferenciación frente a la competencia. A su vez, se pueden conocer los atributos específicos que logran caracterizar la oferta del producto auténtico, que son aceptables para el mercado. En segundo lugar, desde el ángulo táctico, se benefician preliminarmente todos los elementos relacionados con el diseño del producto, el diseño de la cadena de suplido para la distribución de los productos, la comunicación y la tarifación. Veamos las sugerencias gerenciales para el caso específico del suero costeño, como ejemplo de lo que puede proceder producto de la orientación obtenida de los brandcepts. 


\section{DISEÑO DEL PRODUCTO Y SU DISTRIBUCIÓN}

En primer lugar, los atributos del producto a los que se les debería prestar más atención en el diseño y la distribución son los del sabor y la consistencia. Estos fueron señalados recurrentemente por parte de las participantes en expresiones, tales como:

- "El suero costeño nosotros lo identificamos primero que todo en el sabor y en lo espeso... un espeso y un acidito natural".

- "La marca puede que no sea de aquí..., pero que el contenido sea la fórmula de aquí... la fórmula de aquí es espesita... con su sabor acidito... su sal...”

Sin embargo, habría que tomar en consideración que el suero costeño se produce de manera industrial. Esto pudiera significar que una parte del mercado (segmentación) dudaría de su autenticidad. Esto se revela en las siguientes expresiones:

- "Para mí lo original es lo que hace la gente que sabe hacerlo... la gente de pueblo... la gente de casa... pero en una industria... ya eso trae otras cosas, ya eso NO es original, NO es natural... ya eso tiene químico".

- "Mi mamá también conoce de suero... y mi mamá7 dice 'esto está ligao, esto no es suero,' esto como que lo rinden con esto y esto, entonces ya yo así no me arriesgo tampoco a comprarlo".

Las primeras intervenciones de las participantes, en cuanto a definir qué era auténtico y qué no lo era, sugieren que si el empaque facilita y permite verificar las características organolépticas del suero (olor, sabor, consistencia, color), siempre y cuando se asegure su sabor, se puede diferenciar de la presentación de la competencia

${ }^{7}$ Palabra utilizada despectivamente cuando se trata de dar a entender que un producto alimenticio ha sido rebajado en la pureza percibida.

46 ISSN 1541-8561 FORUM EMPRESARIAL VOL. 17. NÚM. 2 INVIERNO 2012-2013 
(según constató uno de los autores, el empaque de la competencia es regularmente en formato sellado, lo cual imposibilita comprobar la autenticación por parte de los clientes (Alexander, 2009). En este sentido, los arreglos en torno al empaque deberían ser dirigidos hacia la transmisión de poco arreglo, sin tanta cosa como hay ahora, como expresaran las participantes.

Segundo, las características de los productos indicados sugieren que la distribución debería estar emplazada en supermercados o centros comerciales, cuyas tiendas ancla sean supermercados, debido a que es el lugar que domina las compras de alimentos del grupo que participó en la sesión (y de otras personas que fueron referidas como potenciales participantes).

Otro aspecto importante es el abastecimiento. Las participantes resaltaron como factor clave de autenticación el sabor ligado al método de producción y el compromiso con la calidad (Beverland, 2005, 2006), y no estrictamente el origen del suero, aunque para efectos de reforzamiento (Porter 1996), el hecho de que el suero provenga del territorio de la región colombiana del Caribe (cuya gente se denomina costeña) puede ser una influencia relevante en la autenticación, siempre que se exponga como atributo (comunicación). Esto amplía las posibilidades de fuentes de abastecimiento, ya que siendo la región colombiana del Caribe territorio que ocupa el $11.6 \%$ del territorio nacional, bien podría recurrirse a pequeñas granjas que fabriquen el producto de forma estandarizada. Incluso se podría introducir en la oferta variedades de suero ligadas a diferentes fuentes de abastecimiento, a características de los ganados, de terrenos, entre otras. Esto le confiere al producto un cierto sentido de misticismo similar al de los vinos con su apelación al terroir (Beverland, 2005, 2006).

\section{Comunicación}

Después de considerar las intervenciones de las participantes, respecto a diferentes categorías de productos y, particularmente, las relacionadas al suero costeño, surge una nueva oferta acerca de este producto que necesitaría la ubicación de su eje comunicativo con 
fines de apoyar su posicionamiento sobre la base de una personalidad excitante con toques de sinceridad y rusticidad (Aaker, 1997). De tal forma, se podrá aprovechar el espacio en el mercado que, en este sentido, permiten los actuales oferentes del producto. Asimismo, la metáfora profunda de conexión (Zaltman y Zaltman, 2008) puede complementar el portafolio de opciones comunicativas en tanto el sabor del suero costeño puede enviar mensajes de asociación con la sabrosura de la personalidad y las manifestaciones culturales costeñas.

Otro de los atributos de comunicación que surgieron en la sesión de grupo es que el nombre de la marca debe mantener más cercanía con la cotidianidad de los consumidores, sin que necesariamente se deba utilizar el apelativo suero costeño para identificar de qué tipo de producto se trata. A este respecto, cuando se les preguntó a las participantes qué nombre o marca le pondrían a un producto de suero costeño, que les trasmitiera el sentido de autenticidad, las respuestas fueron las siguientes: El Suero Mayo, Atoyabuey ${ }^{8}$, el original, Suero Mélanie y Suero Aurora. Como la mayoría alude a nombres personales, se vislumbra que las marcas deban contener una fuerte carga de autenticidad que exalte la identidad. Esta situación es compatible con una de las fuentes de autenticidad de Peterson (2005): la identidad étnico-cultural.

\section{Conclusiones}

La noción de autenticidad, socialmente construida (Beverland, 2005; Grayson y Martinec, 2004; Groves, 2001; Thompson, Rindfleisch y Arfel, 2006; Peterson, 2005), más específicamente, localmente construida (Lu y Fine, 1995), se pudiera utilizar como diferenciador de una oferta (aun cuando la autenticidad no sea determinante de una compra). Incluso, la investigación sugiere que la autenticidad de un producto podría ser aceptada sin mayores reparos por un comprador de un país distinto al que originó el

${ }^{8}$ En el mercado existe ya hay una oferta de suero costeño con este nombre, propiedad de la empresa Colanta. Paradójicamente, esta marca de suero no figuró entre las consumidas por las participantes, siendo que está disponible en la plaza de Cartagena. 
producto, mientras existan garantías o certificaciones del origen del mismo.

Sin embargo, cuando se trata de un producto, por ejemplo, consumido principalmente por grupos étnicos particulares cuya elaboración o producción es asociada a determinadas costumbres, procesos, ingredientes o contenidos, como es el suero costeño, la respuesta de la audiencia a lo que es autenticidad probablemente cuente con matices que influyan significativamente en el comprador, debido a su relación silvestre o cultural con la categoría del producto. Es probable que el comprador espere que todo lo que rodee a dicho producto, incluso su producción, su distribución principal y sus circunstancias de consumo, proyecten dicha cultura. Es también probable que ese mismo grupo cultural compre (y consuma) productos de origen distinto al suyo, con reclamos de autenticidad por los que lo ofertan, sin mayores cuestionamientos sobre dicho reclamo de parte del grupo comprador. Lo descrito es en sí mismo un efecto caleidoscopio de la noción de autenticidad. Es importante destacar que, a pesar de que lo auténtico pueda ser identificado o reconocido, no necesariamente tiene por qué ser aceptado. Por tanto, al gerente de mercadeo le corresponde validar la aceptación antes de plantearla como parte del posicionamiento que diseñe. En esta investigación, el brandcepts de Los Simpson se aceptó como familia, pero no su comportamiento.

Producto de las asociaciones metafóricas que permiten los brandcepts, se accedió a un sinnúmero de emociones que, para el caso de este estudio, recayeron fuertemente en manifestaciones de exaltación de orgullo y de deleite, tanto a nivel genérico como en la categoría de suero costeño. Este resultado confirma la postura de Woods (2004) y de Zaltman y Zaltman (2008) de que las metáforas permiten adentrarse en el inconsciente del ser humano, de manera que se pueden lograr respuestas incapaces de manifestarse con preguntas directas. Por tanto, queda abierta la posibilidad de continuar con futuras exploraciones emocionales, sobre la base de las emociones explícitas a lo largo del estudio, sobre todo aquellas que evoquen origen, tradición y, particularmente, legitimidad. Probablemente, estas lograrán la credibilidad que requiere un producto al momento de posicionarlo como auténtico. 


\section{Referencias}

Aaker, J. (1997). Dimensions of brand personality. Journal of Marketing Research, 34(3), 347-356.

Alexander, N. (2009). Brand authentication: Creating and maintaining brand auras. European Journal of Marketing, 43(3/4), 551-562.

Aprile, O. (2007). La publicidad estratégica. Buenos Aires: Paidós.

Beverland, M. (2005). Crafting brand authenticity: The case of luxury wines. Journal of Management Studies, 42(5), 1003-1029.

Beverland, M. (2006). The 'real thing': Branding authenticity in the luxury wine trade. Journal of Business Research, 59(2), 251-258.

Beverland, M. y Farrely, F. (2010). The quest for authenticity in consumption: Consumers' purposive choice of authentic cues to shape experienced outcomes. Journal of Consumer Research, 36(5), 838-856.

Calder, B. y Tybout, A. (1987). What consumer research is... Journal of Consumer Research, 14, 136-140.

Calonius, H. (1986). A market behavior framework. En K. Möller y M. Paltschik (Eds.), Contemporary Research in Marketing (515-524). Proceedings from the XV Annual Conference of the European Marketing Academy. Helsinki: Helsinki School of Economics and Hanken Swedish School of Economics Finland.

Chitturi, R., Raghunathan, R. y Mahajan, V. (2008). Delight by design: The role of hedonic vs. utilitarian benefits. Journal of Marketing, 72, 48-63.

Cooper, R. (1988). Predevelopment activities determine new product success. Industrial Marketing Management, 17(3), 237-247.

Grayson, K. y Martinec, R. (2004). Consumer perceptions of iconicity and indexicability and their influence on assessment of authentic market offerings. Journal of Consumer Research, 31, 296-312.

Grönroos, C. (2006). On defining marketing: Finding a new roadmap for marketing. Marketing Theory, 6(4), 395-417.

Groves, A. (2001). Authentic British food products: A review of consumer perceptions. International Journal of Consumer Studies, 25(3), 246-254. 
Herrera, C. (2010). Consumiendo. Introducción al consumo y al consumidor colombiano. Bogotá: Alfaomega.

Holbrook, M. (1987). What is consumer research? Journal of Consumer Research, 14, 128-132.

Holt, D. (1998). Does cultural capital structure american consumption? Journal of Consumer Research, 25, 1-25.

Johne, A. (1994). Listening to the voice of the market. International Marketing Review, 11(1), 47-59.

Jones, C., Anand, N. y Alvarez, J. (2005). Manufactured authenticity and creative voice in cultural industries. Journal of Management Studies, 42(5), 893-899.

Kotler, P. y Keller, K. (2006). Marketing management. New Jersey: Prentice-Hall.

Lewis, D. y Bridger, D. (2000). The soul of the new consumer. London: Nicholas Brealey.

Lu, S. y Fine, G. (1995). The presentation of ethnic authenticity: Chinese food as a social accomplishment. The Sociological Quaterly, 36(3), 535-553.

Malhotra, N.K. (2007). Chapter 5: Exploratory research design. En Marketing research: An applied orientation (pp.140-179). New Dehli: Prentice Hall Inc.

Marketingnews.com.co (2010, enero-febrero). "Trece tendencias del estilo de vida del consumidor colombiano" (I). Recuperado de http://www.marketingnews.com.co/site/Secciones/ Investigación/DetalleInvestigación/tabid/238/smid/425/ ArticleID/113/reftab/179/t/TreTrece-tendencias-del-estilode-vida-del-consumidor-colombiano-I/Default.aspx.

Martínez, D. (2009). Valores y creencias en el consumo de comida en los hogares barranquilleros. Pensamiento Ẽ gestión, 27, 1-58.

Moeran, B. (2005). Tricks of the trade: The performance and interpretation of authenticity. Journal of Management Studies, 42(5), 901-922.

Palojoki, P. y Tuomi-Gröhn, T. (2001). The complexity of food choices in an every day context. International Journal of Consumer Studies, 25(1), 15-23.

Peterson, R. (2005). In search of authenticity. Journal of Management Studies, 42(5), 1083-1098. 
Porter, M. (1996). What's strategy? Harvard Business Review, novemberdecember, 1083-1098.

Spiggle, S. (1994). Analysis and interpretation of qualitative data in consumer research. Journal of Consumer Research, 21, 491-503.

Ries, A. y Trout, J. (1981). Positioning: The battle for your mind. New York: McGraw-Hill Book Compay.

Semana.com. (2010, enero 30). No enloqueció. Recuperado de http://www.semana.com/noticias-vida-moderna/ noenloquecio/134319.asp .

Thompson, C., Rindfleisch, A. y Arfel, C. (2006). Emotional branding and the strategic value of the doppelganger brand image. Journal of Marketing, 70, 50-64.

Woods, R. (2004). Exploring the emotional territory for brands. Journal of Consumer Behavior, 3(4), 388-403.

Zaltman, G. y Zaltman, L. (2008). Marketing methaporial. Boston: Harvard Business Press. 